\title{
Expansão da educação a distância no território fluminense: um enfoque multicritério
}

\author{
Luiz Augusto Caldas Pereira ${ }^{1}$ \\ Carla Nogueira Patrão ${ }^{2}$ \\ Milton Erthal ${ }^{3}$
}

\section{RESUMO}

0 presente trabalho tem como objetivo a aplicação prática do método ELECTRE I para apoio à decisão de gestores públicos educacionais, mais precisamente no Instituto Federal Fluminense, na definição dos municípios para implantação de seis novos polos de Educação a Distância. Para a estruturação do trabalho, foi definido que o conjunto de alternativas possíveis seria formado por municípios que integram as mesorregiões Noroeste Fluminense, Norte Fluminense e Baixadas Litorâneas, excluindo aqueles que já contam com campus presencial ou polo de EaD do IFFluminense. 0 processo decisório foi modelado baseando-se em critérios e pesos atribuídos por especialistas. Os resultados alcançados com a aplicação do método Electre I demonstram a utilidade dos métodos multicritérios de apoio à decisão. 0 método Electre I, sem prescindir de aspectos ligados ao decisor, favorece a transparência nos processos decisórios dos gestores. Porém, vale renovar a afirmação de que nenhum tipo de instrumento ou ferramenta pode ser considerado pela sua qualidade que supera a condição de deliberador finalístico do decisor.

PALAVRAS-CHAVE: Decisão multicritério; Electre I; Educação; Formação Profissional.

\section{ABSTRACT}

The present work has the objective of applying the ELECTRE I method to suppport the educational public managers, more precisely in the Fluminense Federal Institute, in the decision of which municipalities should have the implementation of six new poles of distance education. To structure the work, it was defined that the set of possible alternatives would be formed by municipalities that integrate the Noroeste Fluminense, Norte Fluminense and Baixadas Litorâneas mesoregions, excluding those that already have a campus presence or a distance education pole. The decisionmaking process was modeled based on criteria and weights established by experts. The results obtained with the ELECTRE I method demonstrate the usefulness of multicriteria decision support methods. The Electre I method, without dispensing the aspects related to the decision maker, favors transparency in the decision-making processes of the managers. However, it is worth renewing the assertion that no type of instrument or tool can be considered for its quality that surpasses the condition of finalist deliberator of the decision maker

KEY-WORDS: Multicriteria decision. Electre I; Education; Professional qualification.

\section{Introdução}

A Educação a Distância (EaD) tem sido apresentada, no âmbito das políticas educacionais, como alternativa de acesso aos estudantes que não atendem aos requisitos próprios da educação presencial, como a rigidez de horários, a estrutura curricular ou mesmo, a

1 Professor do Instituto Federal Fluminense e doutorando do Programa em Planejamento Regional e Gestão da Cidade, Universidade Candido Mendes, luizcaldas.iff@gmail.com

2 Assistente Social do Instituto Federal Fluminense e doutoranda do Programa em Planejamento Regional e Gestão da Cidade, Universidade Candido Mendes, cnpatrao@gmail.com 
organização da escola. Este descompasso ocorre mais em função das condições de vida do estudante do que pela sua opção.

O tema da EaD ainda tem uma trajetória a percorrer, como política para a educação, se considerarmos a complexidade que envolve a temática, na medida da provocação, dos dias atuais, para desenvolver metodologias que superem as limitações impostas pela realidade que respondam aos desafios de aprendizagem da atualidade e ampliar as oportunidades de ofertas formativas em regiões interioranas com maior dificuldade para o ensino presencial.

Recentemente, Aquino, Pereira e Erthal (2017) propuseram um modelo multicriterial para subsidiar o processo decisório de abertura de novos polos de EaD do Instituto Federal Fluminense (IFFluminense). Neste trabalho, os autores utilizaram o Método de Análise Hierárquica (AHP) com objetivo de subsidiar a distribuição de seis polos EaD nas três mesorregiões do Estado do Rio de Janeiro de atuação do IFFluminense. Esta ferramenta foi relevante ao apresentar uma proposta de partilha dos polos, que sugeriu a implantação de um polo EaD na mesorregião Noroeste Fluminense, dois no Norte Fluminense e três nas Baixadas Litorâneas, excluindo os municípios que já contam com campus presencial ou polo de EaD do IFFluminense.

No entanto, a definição destes seis municípios ficou em aberto com o estudo conduzido por Aquino, Pereira e Erthal (2017), o que motivou a continuidade da pesquisa a fim de se definir a localização destes novos polos EaD. Assim, as seguintes questões foram ponderadas. Que critérios são relevantes para responder este problema? Diante destes, qual método de auxílio multicritério à decisão poderia ser empregado na modelagem deste problema? Com base nestas questões de pesquisa, o objetivo central deste estudo é aplicar um modelo de decisão que auxilie os gestores educacionais a definirem os municípios para implantação de novos polos de EaD. Na tentativa de se obter um conjunto de alternativas viáveis de escolha, os autores optaram pelo método Electre I, uma vez que este método atende às características do problema, com diversas alternativas a serem escolhidas em função de mais de um parâmetro; como também vem sendo muito utilizado para problemas de localização.

Para o desenvolvimento deste estudo, o processo decisório será modelado com base nos cinco critérios a seguir: o número de habitantes na faixa etária de 15 a 39 anos, o número de matrículas no ensino médio por município, o Índice de Desenvolvimento da Educação Básica (IDEB) municipal referente à $8^{\circ}$ série e ao $9^{\circ}$ ano do Ensino Fundamental, o Índice de Desenvolvimento Humano Municipal (IDHM) e a distância rodoviária entre municípios.

Este Artigo está estruturado da seguinte forma: inicialmente o método Electre I será descrito, em seguida é explicada a metodologia adotada, a aplicação do método para a definição dos municípios por mesorregião, os resultados e as considerações finais.

\section{Referencial Teórico}

O Apoio Multicritério à Decisão (AMD) é utilizado em situações (problemas ou oportunidades) em que o decisor precisa analisar um conjunto de alternativas, considerando critérios que se complementam ou são conflitantes entre si. Assim, o AMD apresenta soluções para problemas complexos que servem de apoio ao decisor, identificando alternativas viáveis de ação (ALMEIDA, 2013).

Os métodos de AMD são estruturados com alguns elementos relevantes que compõem o processo decisório: a) decisor - que pode ser um indivíduo ou um grupo de indivíduos com atribuição de avaliar as alternativas disponíveis para fazer a melhor escolha; b) analista indivíduo ou equipe responsável pela modelagem do problema e que irá recomendar a 
melhor solução; c) alternativas - que formam o conjunto sobre a qual a escolha será realizada; d) atributos ou critérios - que são os eixos de avaliação que vão direcionar a análise das alternativas para a melhor escolha; e) pesos - que são as medidas da importância relativa que cada critério tem para o decisor; f) tipos de problema - que são apresentados no Quadro 1 (GOMES et al, 2004).

Quadro 1: Tipos de problema comuns na tomada de decisão multicriterial.

\begin{tabular}{|c|l|}
\hline PROBLEMA & \multicolumn{1}{c|}{ PROBLEMÁTICA ABORDADA } \\
\hline$P(a)$ & Selecionar a "melhor" alternativa ou as melhores alternativas \\
\hline$P(\beta)$ & $\begin{array}{l}\text { Aceitar alternativas que parecem "boas" e descartar as que parecem "ruins", isto é, } \\
\text { classificar as alternativas }\end{array}$ \\
\hline$P(\gamma)$ & Gerar uma ordenação das alternativas \\
\hline$P(\delta)$ & Realizar uma descrição das alternativas \\
\hline
\end{tabular}

Fonte: Gomes et al (2004).

Atualmente existem muitas metodologias em AMD, que se aplicam aos mais diversos problemas. Neste Artigo, tendo como base as características do problema de pesquisa, o enfoque foi sobre a Escola Francesa de AMD, que tem a família Electre (Elimination et Choix Traduissamt la Réalité), proposta por Bernard Roy na década de 1960, como um dos principais métodos (FIGUEIRA et al., 2005). O método Electre vem sendo aprimorado com outras ferramentas da Pesquisa Operacional, tornando-o um dos métodos mais utilizados atualmente. Há várias versões do método Electre (I, II, III, IV, IS e TRI), sendo que todas seguem o mesmo princípio de sobreclassificação, outranking ou surclassment, em que há superação ou prevalência entre as alternativas.

O Electre I é apropriado para problemas do tipo Pa, sendo, portanto, apropriado para se determinar um subconjunto que contenha as melhores alternativas. Este método estabelece um mínimo subconjunto dominante (K), que contém pelo menos uma alternativa que não é superada por nenhuma outra (MELLO et al., 2005; SIQUEIRA e FILHO, 2011). Ao contrário dos métodos da escola americana, como o AHP e a teoria multiatributo, em que as comparações são realizadas por agregação, os métodos da família ELECTRE, da escola francesa, utilizam a noção de relação de superação (outraking methods). Segundo Roy e Bouyssou (1993), a obtenção de uma solução robusta a partir do Electre I implica atender os seguintes axiomas: a) da exaustividade, que consiste na descrição do problema com atenção a todos os pontos relevantes; b) da coesão, que é a análise precisa da importância das alternativas em cada critério; c) e a não redundância, que consiste na eliminação de itens que possuem características similares a outros.

Conforme afirma Elgün (2011), há várias possibilidades de responder a problemas que envolvem a escolha de locais, que vão desde os métodos intuitivos àqueles que têm como suporte modelos estatísticos e matemáticos. Dentre os métodos multicritério, o autor cita, para estes casos, o Processo de Análise Hierárquica (AHP), o Método Delphi e o Método ELECTRE.

Segundo Costa (2016) e Almeida (2016), o método Electre I pode ser dividido em duas etapas. Na primeira determinam-se as relações de sobreclassificação (outranking), a partir da comparação par a par entre as alternativas. Esta comparação é estabelecida por uma relação de superação, onde uma determinada alternativa $a$ supera a alternativa $b$ (aSb) se $a$ for, pelo menos, tão boa quanto $b$. Na segunda etapa, estas relações são exploradas com a finalidade de se obter um subconjunto de alternativas que represente a solução do problema. O conjunto de alternativas escolhido não deve ser sobreclassificado por nenhum outro conjunto. 
Outros métodos da família Electre usam outras relações de preferências, além da superação (aSb), como a preferência estrita (aPb), preferência fraca (aQb) ou indiferença (alb) (GOMES et al, 2004). Em alguns casos, há conjuntos que são incomparáveis, o que resulta em mais de uma solução para o problema.

A construção das relações de sobreclassificação baseia-se nos índices de concordância e discordância. $O$ índice de concordância, $C(a, b)$, definido pela equação 1 , é obtido pela soma de todos os pesos dos critérios $i$ no caso em que a alternativa $a$ supere $b$ (aSb), isto é, $a$ tem a maior parte dos pesos dos critérios a seu favor.

$$
C(a, b)=\sum_{i: g_{i}(a) \geq g_{i}(b)} p_{i}, \text { sendo } \sum_{i} p_{i}=1
$$

[Eq. 1]

O índice de discordância $D(a, b)$, calculado pela equação 2 , representa a desvantagem da alternativa $a$ em relação à alternativa $b$, para os critérios em que $b$ é o vencedor. De forma prática, o índice de discordância pode ser entendido como um veto à concordância de que aSb, calculada por $C(a, b)$. Por analogia, é como ouvir e reconhecer as minorias, ou seja, dar notoriedade aos critérios onde $b$ é vencedor, para o caso da vantagem de $b$ estar 'acima de certo valor admissível para qualquer desses critérios' (ALMEIDA, 2013, p. 113). Ambos os índices devem ser normalizados para que sejam analisados em uma escala de valor entre 0 e 1.

$$
D(a, b)=\max \left[\frac{g_{i}(b)-g_{i}(a)}{\text { sscala }_{i}}\right], \forall i g_{i}(b)>g_{i}(a)
$$

De acordo com Bernard Roy (COSTA, 2016), para que se tenha a relação de sobreclassificação é necessário que se atendam a duas condições:

$$
\text { aSb se e somente se }\left\{\begin{array}{l}
\mathrm{C}(\mathrm{a}, \mathrm{b}) \geq \bar{c} \\
\mathrm{D}(\mathrm{a}, \mathrm{b}) \leq \bar{d}
\end{array}\right.
$$

A Figura 1 ilustra estas duas condições. O bando de pássaros é tomado como exemplo para, por analogia, representar o conjunto de alternativas de uma situaçãoproblema. Conforme se observa, nem todos os sete pássaros conseguem atender, simultaneamente, às duas condições, ou seja, superar os obstáculos (c) e (d). Desta forma, os três pássaros que conseguem tal feito, assumem, portanto, a relação $a$ supera $b$.

Figura 1: Representação da relação ' $a$ ' supera ' $b$ ' em um dado critério.

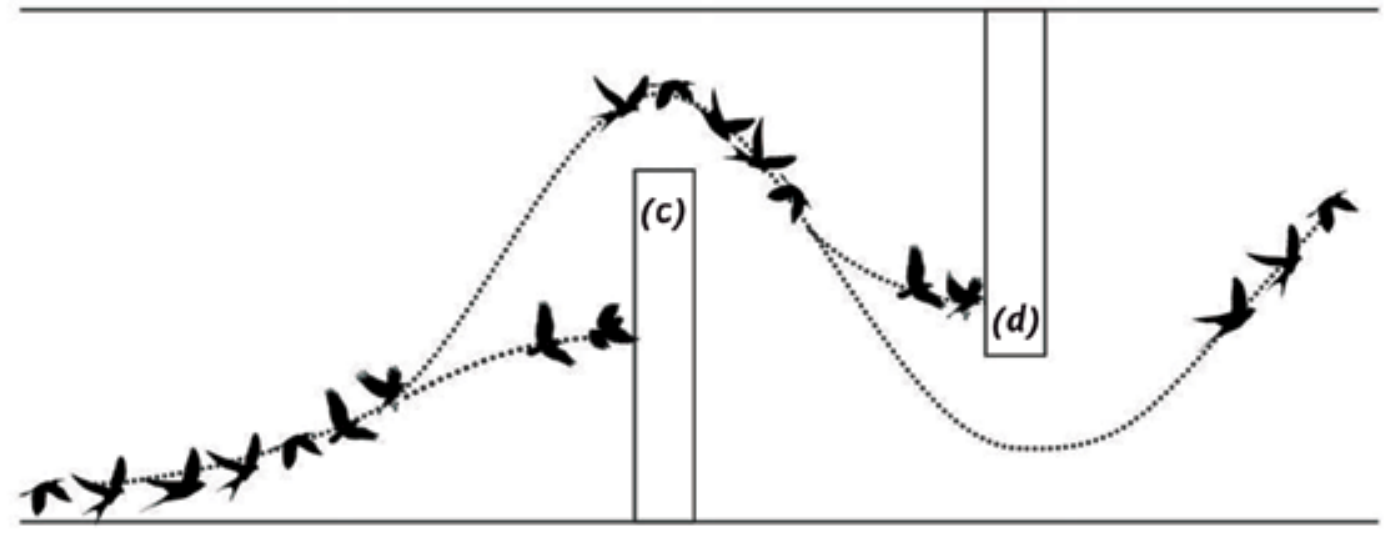

Fonte: Laboratório Experimental de Design Gráfico do IFFluminense, com base em Costa (2016). 
Após a construção das relações de superação entre cada par de alternativas, são construídos grafos no método Electre I, conforme exemplificado na Figura 2.

Figura 2: Relações de sobreclassificação

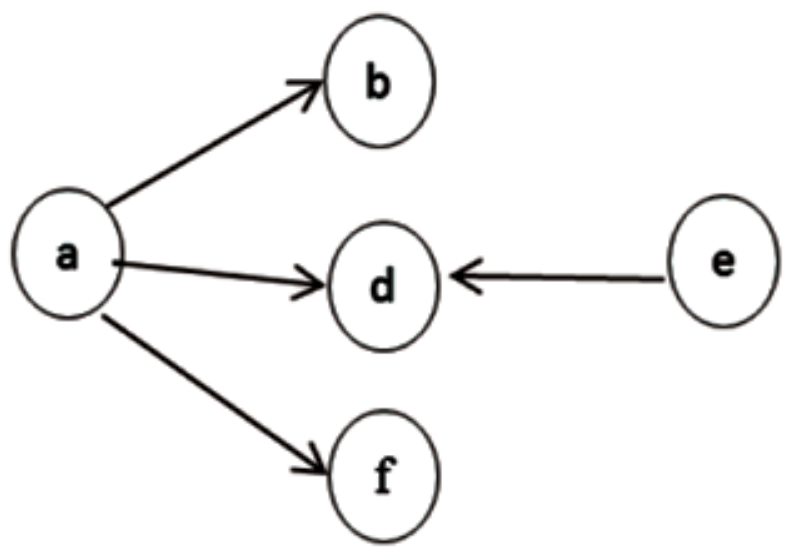

Fonte: Costa (2016).

A partir da construção do grafo, o Electre I divide o conjunto de alternativas em dois subconjuntos: um subconjunto não-dominado $(\mathrm{N})$ e um que domina (D), tendo duas regras a seguir:

- Regra 1: não há relação de sobreclassificação (outranking) entre todas as alternativas em N.

- Regra 2: todas as alternativas em D são superadas por, pelo menos, uma alternativa em N.

A escolha das alternativas está fundamentada na teoria de grafos. Importante destacar que o sentido da seta é referência indicativa da condição de sobreclassificação. Observando-se a Figura 2, as setas com origem em $a$ e em e significam que estes dois elementos são tomados como sobreclassificadores. Do outro lado, as setas que têm como destino $b, d$ e $f$ define-os como sobreclassificados.

Assim, aplicando-se as regras 1 e 2 acima sobre o grafo da Figura 2, temos os seguintes subconjuntos:

$$
\begin{array}{ll}
N= & \{a ; e\} \\
D= & \{b ; d ; f\}
\end{array}
$$

Importante ressaltar que os resultados do Electre I implicam que o conjunto $\mathrm{N}$ ultrapassa o subconjunto $\mathrm{D}$, o que não implica que todas as alternativas em $\mathrm{N}$ sobreclassificam todas as alternativas em D. Assim, Electre I resulta em uma relação outranking entre os conjuntos $\mathrm{N}$ e D e não, a relação entre alternativas individualmente (COSTA, 2016).

Segundo Roy e Bouyssou (1993), o método Electre I deve ser difundido em várias áreas. Primeiro, devido ao conceito de sobreclassificação que está contido nele. E segundo, pelo

alto grau de simplicidade das fórmulas que definem um sistema e que já foram bem sucedidas em esclarecer problemas de apoio à decisão multicritério cada vez mais complexos com o passar do tempo. 


\section{Procedimentos metodológicos}

O Artigo refere-se a uma pesquisa descritiva e aplicada (SILVA e MENEZES, 2005, p.20), com objetivo de resolver um problema real de uma instituição de ensino que precisa definir os municípios para a implantação de polos de EaD.

A etapa metodológica foi estruturada em quatro fases. Primeiro, foram identificados os critérios relevantes para a definição de em quais municípios por mesorregião devem ser implantados novos polos EaD do IFFluminense ${ }^{4}$. Em seguida, foi aplicado questionário a três especialistas com a finalidade de conferir notas (de 01 a 10) aos critérios. Após esta etapa, os autores, com base nas notas dadas pelos especialistas, distribuíram pesos de 01 a 05 a cada critério. E por fim, foram aplicadas as fórmulas do método Electre I para solucionar o problema de localização de polos EaD do IFFluminense, assim denominados: a) problema I, escolha de dois municípios na mesorregião Norte Fluminense; b) problema II, escolha de um município na mesorregião Noroeste Fluminense; c) problema III, escolha de três municípios na mesorregião Baixadas Litorâneas expandidas ${ }^{5}$.

A situação-problema apresentada neste Artigo estrutura-se em elementos básicos, relevantes que compõem o processo decisório:

- Decisor: Conselho Superior do IFFluminense, órgão superior, de caráter consultivo e deliberativo;

- Analista: os autores deste Artigo;

- Alternativas: o conjunto de 20 municípios distribuídos por mesorregião, à exceção daqueles municípios com campi presenciais ou com polo de EaD já instituído (ver quadro 2);

- Atributos ou critérios: critérios apresentados no Quadro 3;

- Pesos dos critérios: pesos atribuídos de 01 a 05, considerando a avaliação de 3 especialistas;

- Tipo de problema: localizar, a partir de multicritério, em quais municípios, por mesorregião, devem ser implantados os novos polos EaD do IFFluminense.

Quadro 2: Quadro-síntese do estudo

\begin{tabular}{|c|c|c|c|}
\hline PROBLEMA & Nº DE MUNICÍPIOS & MESORREGIÃO & ALTERNATIVAS \\
\hline I & 02 & Norte Fluminense & $\begin{array}{l}\text { Cardoso Moreira } \\
\text { São Fidélis } \\
\text { São Francisco de Itabapoana } \\
\text { Carapebus } \\
\text { Conceição de Macabu }\end{array}$ \\
\hline II & 01 & Noroeste Fluminense & $\begin{array}{l}\text { Italva } \\
\text { Laje do Muriaé } \\
\text { Natividade } \\
\text { Porciúncula } \\
\text { Varre-Sai } \\
\text { Aperibé } \\
\text { São José de Ubá } \\
\text { Itaocara }\end{array}$ \\
\hline III & 03 & Baixadas Litorâneas expandida & $\begin{array}{l}\text { Rio das Ostras } \\
\text { Silva Jardim } \\
\text { Araruama } \\
\text { Armação dos Búzios } \\
\text { Iguaba Grande } \\
\text { São Pedro da Aldeia } \\
\text { Saquarema }\end{array}$ \\
\hline
\end{tabular}

Fonte: Autoria própria.

4 Mais informações ver https://periodicos.utfpr.edu.br/rts/article/view/5296.

$5 \quad$ Conjunto de municípios integrantes da mesorregião das Baixadas Litorâneas mais os municípios de Itaboraí e Maricá. 


\section{Critérios}

A técnica de coleta de dados desta pesquisa foi realizada em bases de dados (IBGE, INEP, PNUD), softwares (Google Earth) e por aplicação de questionários. As bases de dados e o aplicativo Google Earth foram usados para a obtenção das variáveis sobre os critérios usados no problema apresentado (Quadro 3).

Quadro 3: Variáveis, justificativas e fontes utilizadas para resolução do problema

\begin{tabular}{|c|c|c|c|}
\hline VARIÁVEL (CRITÉRIO) & JUSTIFICATIVA DOS CRITÉRIOS & FONTE & DIREÇÃO DO VETOR \\
\hline $\begin{array}{l}\text { Número de habitantes na faixa } \\
\text { etária de } 15 \text { a } 39 \text { anos }\end{array}$ & $\begin{array}{l}\text { O Censo EaD Brasil } 2012 \text { aponta que } 93 \% \text { dos } \\
\text { estudantes em cursos de EaD estão na faixa } \\
\text { etária de } 18 \text { a } 40 \text { anos. Assim, por aproximação } \\
\text { dos dados disponibilizados por faixa etária pelo } \\
\text { IBGE, adotou-se a faixa de } 15 \text { a } 39 \text { anos. }\end{array}$ & IBGE/ Censo 2010 & Maximização \\
\hline $\begin{array}{l}\text { Número de matrículas no ensino } \\
\text { médio por município no ano de } \\
2015\end{array}$ & $\begin{array}{l}\text { A educação profissional se apresenta como } \\
\text { alternativa de profissionalização para jovens e } \\
\text { adultos no decorrer do ensino médio. }\end{array}$ & INEP/MEC & Maximização \\
\hline $\begin{array}{l}\text { Índice de Desenvolvimento } \\
\text { da Educação Básica (IDEB) } \\
\text { municipal referente à } 8^{\circ} \\
\text { série e ao } 9^{\circ} \text { ano do Ensino } \\
\text { Fundamental no ano de } 2015\end{array}$ & $\begin{array}{l}\text { O IDEB é calculado a partir de dois } \\
\text { componentes: a taxa de rendimento escolar } \\
\text { (aprovação) e as médias de desempenho na } \\
\text { Prova Brasil, no caso de escolas e municípios. }\end{array}$ & INEP/MEC & Minimização \\
\hline $\begin{array}{l}\text { Índice de Desenvolvimento } \\
\text { Humano Municipal (IDHM) } 2010\end{array}$ & $\begin{array}{l}\text { O IDHM considera em seu cálculo três } \\
\text { componentes: longevidade, educação e renda } \\
\text { e, muitas vezes, uma alteração positiva no } \\
\text { índice não significa que os três elementos se } \\
\text { movimentaram no mesmo sentido, mesmo } \\
\text { que seja já consagrada a relação diretamente } \\
\text { relacionada entre os elementos. Assim, na } \\
\text { resolução do problema, o IDHM será o único } \\
\text { critério analisado em sentido contrário, ou seja, } \\
\text { quanto menor o IDHM, mais valorizado será o } \\
\text { critério no contexto. }\end{array}$ & PNUD & Maximização \\
\hline $\begin{array}{l}\text { Distância rodoviária entre } \\
\text { munícipios }\end{array}$ & $\begin{array}{l}\text { Dentro da perspectiva de integração territorial } \\
\text { dos Institutos Federais, a distância entre } \\
\text { municípios visa valorizar municipios mais } \\
\text { distantes dos atuais campi e polos EaD do } \\
\text { IFFluminense em que as oportunidades de } \\
\text { acesso à formação profissional são menos } \\
\text { acessíveis. }\end{array}$ & Google Earth & Maximização \\
\hline
\end{tabular}

Com a finalidade de atribuir pesos aos critérios, primeiro, foi aplicado questionário para que especialistas avaliassem as variáveis referentes à situação-problema, considerando intervalo de notas de 01 a 10. A partir desta avaliação, os autores correlacionaram as notas aos graus de importância (baixo, moderado e alto). A partir desta correlação, atribui-se os pesos de 01 a 05 aos critérios, observando-se o grau de importância majoritário em cada critério. Em seguida, como apresentado na Tabela 1, procedeu-se à normalização dos pesos dos critérios, processo em que há uma transformação na escala de avaliação, com intervalo de $(0,1)$, em que o valor zero significa a menor preferência e o valor 1 , a maior preferência (ALMEIDA, 2013). Os pesos normalizados são utilizados na resolução dos problemas deste Artigo.

Segundo visão dos especialistas, o critério 'distância rodoviária' que refere-se à distância rodoviária entre a cidade candidata a receber um polo de EaD e o campus mais próximo do IFFluminense, representa a condição majoritária do grau de importância alto e, por esta razão, recebeu peso 5. Os critérios 'IDHM' e o 'IDEB' receberam a mesma avaliação (duas avaliações moderadas e uma baixa), o que deveria se traduzir em pesos iguais. Neste caso, 
os autores optaram em atribuir peso 4 para 'IDHM' e peso 3 para 'IDEB', considerando que o IDEB é consequência de uma condição mais ajustada ao desempenho do IDHM, na medida em que o desenvolvimento humano está atrelado também às condições favoráveis na educação escolar, o que afeta a qualidade de vida das pessoas. Por fim, os critérios ' $N^{\circ}$ de habitantes' e ' $N^{\circ}$ de matrículas no ensino médio' também deveriam ter ponderações de pesos semelhantes, pois receberam duas avaliações baixas e uma alta. Assim, os autores atribuíram os pesos 1 e 2 aos critérios, respectivamente; justificando pela natureza do problema, por se tratar de uma política educacional, ou seja, número de matrículas impulsiona a demanda por formação profissional.

Tabela 1: Tratamento referente aos pesos dos critérios

\begin{tabular}{c|ccccc}
\hline \multirow{2}{*}{ Especialistas } & No de habitantes & $\begin{array}{c}N^{0} \text { de matrículas no } \\
\text { ensino médio }\end{array}$ & IDEB municipal & IDHM & $\begin{array}{c}\text { Distância rodoviária } \\
\text { entre munícipios }\end{array}$ \\
\cline { 2 - 6 } & Grau de importância & Grau de importância & Grau de importância & Grau de importância & Grau de importância \\
\hline A & Alto & Baixo & Baixo & Baixo & Moderado \\
\hline B & Baixo & Alto & Moderado & Moderado & Alto \\
\hline C & Baixo & Baixo & Moderado & Moderado & Alto \\
\hline Pesos & 1 & 2 & 3 & 4 & 5 \\
\hline Pesos normalizados & 0,067 & 0,267 & 0,133 & 0,200 & 0,333 \\
\hline
\end{tabular}

\section{Resultados}

O problema de localização de polos EaD caracteriza-se por uma situação típica de aplicação de método multicritério de auxílio à decisão. No contexto deste Artigo, são apresentados 03 problemas, denominados de I, II e III, referentes à definição dos municípios por mesorregião para localização de novos polos EaD, conforme descrito no Quadro 3. A seguir, são apresentados os resultados para cada um dos três problemas deste artigo

\section{i) Problema I}

A Tabela 2 apresenta os dados quantitativos de cada alternativa em relação aos critérios e os pesos normalizados referentes aos cinco municípios candidatos a receberem um polo EaD na mesorregião Norte Fluminense. Os municípios de São Fidelis (A2) e São Francisco do Itabapoana (A3) se destacam nos critérios 'Habitantes', 'Matrículas EM' e 'Distância rodoviária'. Os municípios de Carapebus (A4) e Conceição de Macabu (A5) se destacam no critério 'IDHM', enquanto que São Francisco de Itabapoana (A3) e Carapebus (A4) se destacam no critério 'IDEB'.

Observado os dados da Tabela 2 pode-se notar que algumas alternativas apresentam um bom desempenho em alguns critérios, mas não se destacam em outros. Além disso, alguns critérios, como 'distância rodoviária', tem um peso maior, enquanto que outros, como 'Habitantes', impactam pouco na modelagem. Estas características são típicas de problemas complexos que podem ser abordados com metodologias de Apoio Multicritério à Decisão. Para explicar como estes modelos funcionam, Almeida (2013) traz a ideia de uma balança, em que cada critério encontra-se relacionado às colunas da balança, formando a coluna dos prós e dos contras. Assim, ao confrontarse os critérios, em função de seu grau de importância, utilizando o procedimento para eliminação de argumentos prós e contras, um lado da balança penderá, o que equivale a dizer que uma coluna terá maior peso. 
Tabela 2: Desempenho das alternativas (An) a luz dos critérios. Entre parênteses os valores normalizados

\begin{tabular}{lccccc}
\hline \multirow{2}{*}{ ALTERNATIVAS } & \multicolumn{3}{c}{ CRITÉRIOS } \\
\cline { 2 - 6 } & $\begin{array}{c}\text { Habitantes } \\
\text { (número total) }\end{array}$ & IDHM & $\begin{array}{c}\text { Matrículas EM } \\
\text { (número total) }\end{array}$ & IDEB & $\begin{array}{c}\text { Distância } \\
\text { rodoviária } \\
\text { (em Km) }\end{array}$ \\
\hline Cardoso Moreira (A1) & 4.808 & 0,648 & 337 & 4,2 & $34,8^{1}$ \\
São Fidélis (A2) & $(0,099)$ & $(0,190)$ & $(0,084)$ & $(0,204)$ & $(0,163)$ \\
\cline { 2 - 6 } & 12.957 & 0,691 & 1.222 & 4,3 & $53,9^{1}$ \\
São Francisco de Itabapoana (A3) & $(0,268)$ & $(0,203)$ & $(0,305)$ & $(0,209)$ & $(0,253)$ \\
\cline { 2 - 6 } & 16.592 & 0,639 & 1.210 & 4,0 & $50,9^{1}$ \\
Carapebus (A4) & $(0,343)$ & $(0,188)$ & $(0,302)$ & $(0,194)$ & $(0,239)$ \\
\cline { 2 - 6 } & 5.553 & 0,713 & 399 & 4,0 & $25,6^{2}$ \\
Conceição de Macabu (A5) & $(0,115)$ & $(0,210)$ & $(0,100)$ & $(0,194)$ & $(0,120)$ \\
\cline { 2 - 6 } & 8.478 & 0,712 & 834 & 4,1 & $47,7^{2}$ \\
\hline
\end{tabular}

Legenda:

1 = Distância entre o município e aquele com campus presencial mais próximo, neste caso, o município de Campos dos Goytacazes;

2 = Distância entre o município e aquele com campus presencial mais próximo, neste caso, o município de Quissamã; IDHM = Índice de Desenvolvimento Humano Municipal; IDEB = İndice de Desenvolvimento da Educação Básica, Matrículas EM = matrículas no Ensino Médio.

$3=$ Entre 15 e 39 anos.

Após, são calculados os índices de concordância aplicando a [Eq. 1], cujo resultado final pode ser observado na Figura 3.

$$
C(a, b)=\sum_{i: g_{i}(a) \geq g_{i}(b)} p_{i} \text { onde } a \text { supera } b
$$

[Eq. 1]

Figura 3: Matriz de Concordância

$$
\mathrm{C}=\left[\begin{array}{ccccc} 
& 0,267 & 0,200 & 0,800 & 0,467 \\
0,733 & & 0,666 & 1 & 1 \\
0,800 & 0,334 & & 0,800 & 0,800 \\
0,200 & 0 & 0 & & 0,267 \\
0,533 & 0 & 0,200 & 1 &
\end{array}\right.
$$

Fonte: Autoria própria.

Em seguida, são calculados os índices de discordância, aplicando a [Eq. 2] e efetuando os cálculos para todos os pares de alternativas, conforme Figura 4.

$$
D(a, b)=\max \left[\frac{g_{i}(b)-g_{i}(a)}{\text { Escala }_{i}}\right], \forall i g_{i}(b)>g_{i}(a) \text { onde } a \text { é superado por } b \text { [Eq. 2] }
$$




$$
D=\left[\begin{array}{ccccc}
\hline & 0,908 & 1 & 0,063 & 0,510 \\
0,052 & & 0,308 & 0 & 0 \\
0,040 & 0,060 & & 0 & 0,020 \\
0,177 & 0,844 & 0,940 & & 0,446 \\
0,080 & 0,398 & 0,689 & 0 &
\end{array}\right.
$$

A última etapa consiste na elaboração da matriz de superação, que deve ser estabelecida com base em limiares aceitáveis a serem definidos pela equipe decisória. Este limiar indica o quanto a equipe está disposta a aceitar pequenas diferenças no julgamento par a par entre as alternativas. Neste Artigo, foram definidos para os limiares de Concordância (c) e de Discordância (d), os valores 0,7 e 0,3 , respectivamente. De acordo com a equação 3 , aos índices que atenderam a condição de maior ou igual a 0,7 e de menor ou igual a 0,3 , foi atribuído o valor 1 , e aos que não atenderam às duas condições simultaneamente, foi atribuído o valor 0 (Figura 5).

Figura 5: Matriz de Superação

\begin{tabular}{cccccc|}
\hline & $A 1$ & $A 2$ & $A 3$ & $A 4$ & $A 5$ \\
$A 1$ & - & 0 & 0 & 1 & 0 \\
$A 2$ & 1 & - & 0 & 1 & 1 \\
$A 3$ & 1 & 0 & - & 1 & 1 \\
$A 4$ & 0 & 0 & 0 & - & 0 \\
$A 5$ & 0 & 0 & 0 & 1 & - \\
\hline
\end{tabular}

Fonte: Autoria própria.

Com base na matriz de superação é possível selecionar o grupo de alternativas que se sobrepõem às demais. A interpretação desta matriz pode ser analisada de forma ilustrativa a partir da teoria dos grafos. Um grafo é elaborado analisandose cada linha da matriz de superação, que representa o desempenho de cada uma das alternativas em relação às demais. $O$ valor zero indica que a alternativa não supera a outra, enquanto que o valor um indica que a alternativa é superior no julgamento par a par. Para exemplificar esta relação de superação observe a primeira linha desta matriz que apresenta o desempenho da alternativa 01 (A1).

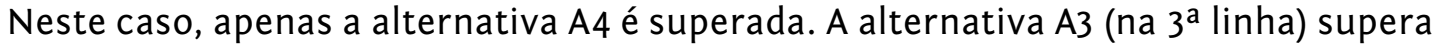
A1, A4 e A5, mas não supera a alternativa A2. Quando não há relação de superação mútua (ambas não se superam), significa que ambas devem compor o grupo de alternativas selecionadas. Este grupo também será composto pelas alternativas que superam todas as demais. A Figura 6 apresenta o kernel das relações de superação apresentados Figura 5. As setas que partem de uma alternativa em direção a outra indica uma relação de superação. $O$ grafo da Figura 6 indica que os municípios de 
São Fidelis (A2) e São Francisco do Itabapoana (A3) superam as demais alternativas e, portanto, devem ser priorizados para a implantação de novos polos de EaD.

Figura 6: Relação de sobreclassificação das alternativas

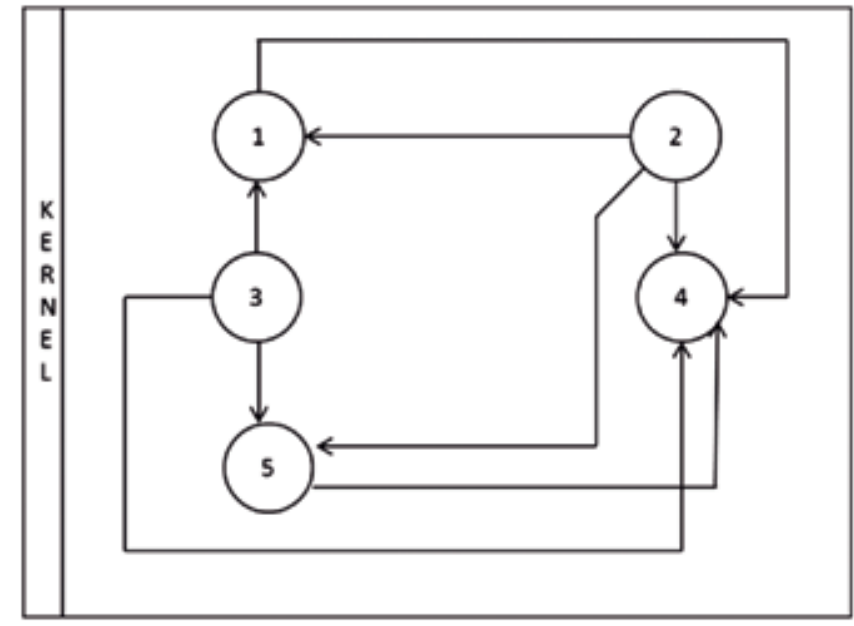

Fonte: Autoria própria.

\section{ii) Problema II}

O segundo problema abordado neste trabalho propõe-se a selecionar um município na mesorregião Noroeste Fluminense. A Tabela 3 apresenta o desempenho dos municípios candidatos a receber um polo EaD. Outros municípios localizados nesta mesma região, já contemplados com pelo menos uma unidade do IFFluminense, foram excluídos do conjunto de alternativas.

Pode-se observar na Tabela 3 que os municípios de Porciúncula (A4) e Itaocara (A8) se destacam nos critérios 'Habitantes' e 'Matrículas EM'. Os municípios de Varre-Sai (A5) se destaca no critério 'Distância rodoviária', enquanto que Natividade (A3) e Itaocara (A8) se destacam no critério 'IDHM' e Laje do Muriaé no IDEB.

Tabela 3: desempenho das alternativas (An) a luz dos critérios. Entre parênteses os valores normalizados

\begin{tabular}{|c|c|c|c|c|c|}
\hline \multirow[b]{2}{*}{ ALTERNATIVAS } & \multicolumn{5}{|c|}{ CRITÉRIOS } \\
\hline & $\begin{array}{l}\text { Habitantes } \\
\text { (número total) }\end{array}$ & IDHM & $\begin{array}{l}\text { Matrículas EM } \\
\text { (número total) }\end{array}$ & IDEB & $\begin{array}{c}\text { Distância } \\
\text { rodoviária } \\
\text { (em Km) }\end{array}$ \\
\hline \multirow{2}{*}{ Italva (A1) } & 5.144 & 0,688 & 408 & 5,2 & $42,8^{1}$ \\
\hline & $(0,214)$ & $(0,125)$ & $(0,118)$ & $(0,144)$ & $(0,161)$ \\
\hline \multirow[t]{2}{*}{ Laje do Muriaé (A2) } & 2.838 & 0,668 & 256 & 3,8 & $31,5^{1}$ \\
\hline & $(0,130)$ & $(0,121)$ & $(0,074)$ & $(0,105)$ & $(0,119)$ \\
\hline \multirow[t]{2}{*}{ Natividade (A3) } & 5.587 & 0,730 & 519 & 4,4 & $32,2^{1}$ \\
\hline & $(0,072)$ & $(0,133)$ & $(0,150)$ & $(0,122)$ & $(0,121)$ \\
\hline \multirow[t]{2}{*}{ Porciúncula (A4) } & 6.862 & 0,697 & 603 & 4,5 & $43,5^{1}$ \\
\hline & $(0,141)$ & $(0,127)$ & $(0,174)$ & $(0,125)$ & $(0,164)$ \\
\hline \multirow[t]{2}{*}{ Varre-Sai (A5) } & 3.919 & 0,659 & 336 & 4,1 & $50,0^{1}$ \\
\hline & $(0,173)$ & $(0,120)$ & $(0,097)$ & $(0,114)$ & $(0,188)$ \\
\hline \multirow[t]{2}{*}{ Aperibé (A6) } & 4.014 & 0,692 & 296 & 4,9 & $16,1^{2}$ \\
\hline & $(0,099)$ & $(0,126)$ & $(0,086)$ & $(0,136)$ & $(0,061)$ \\
\hline
\end{tabular}




\begin{tabular}{lccccc}
\hline & \multicolumn{5}{c}{ CRITÉRIOS } \\
\cline { 2 - 6 } ALTERNATIVAS & $\begin{array}{c}\text { Habitantes } \\
\text { (número total) }\end{array}$ & IDHM & $\begin{array}{c}\text { Matrículas EM } \\
\text { (número total) }\end{array}$ & IDEB & $\begin{array}{c}\text { Distância } \\
\text { rodoviária } \\
\text { (em Km) }\end{array}$ \\
\hline São José de Ubá (A7) & 2.803 & 0,652 & 242 & 4,2 & $28,4^{1}$ \\
\cline { 2 - 6 } & $(0,101)$ & $(0,119)$ & $(0,070)$ & $(0,116)$ & $(0,107)$ \\
\hline Itaocara (A8) & 8.484 & 0,713 & 802 & 5,0 & $21,3^{2}$ \\
\cline { 2 - 6 } & $(0,071)$ & $(0,130)$ & $(0,232)$ & $(0,139)$ & $(0,080)$ \\
\hline
\end{tabular}

\section{Legenda:}

1 = Distância entre o município e aquele com campus presencial mais próximo, neste caso, o município de Itaperuna;

2 = Distância entre o município e aquele com campus presencial mais próximo, neste caso, o município de Santo Antônio de Pádua; IDHM = Índice de Desenvolvimento Humano Municipal; IDEB = Índice de Desenvolvimento da Educação Básica, Matrículas EM = matrículas no Ensino Médio.

$3=$ Entre 15 e 39 anos.

Fonte: Os autores com base nos dados do IBGE, INEP, PNUD e Google Earth.

A Figura 7 apresenta a matriz de concordância do Problema II. Esta matriz apresenta os valores em que se assume uma relação de superação entre alternativas em uma comparação pareada dentro de cada critério. A Figura 8, por outro lado, apresenta as situações onde a relação de superação, dentro de um determinado intervalo ' $q$ ', é aceitável. Neste trabalho o valor de 'q' foi de 0,2.

A Figura 9 apresenta a matriz de superação, que é elaborada a partir das matrizes de concordância (Figura 7) e de discordância (Figura 8).

Figura 7: Matriz de Concordância

$$
\mathrm{C}=\left[\begin{array}{cccccccc} 
& 0,733 & 0,800 & 0,467 & 0,400 & 1 & 0,733 & 0,800 \\
0,267 & & 0,267 & 0,267 & 0 & 0,600 & 0,533 & 0,600 \\
0,200 & 0,733 & & 0 & 0,400 & 0,533 & 0,733 & 0,333 \\
0,533 & 0,733 & 1 & & 0,400 & 0,533 & 0,733 & 0,600 \\
0,600 & 1 & 0,600 & 0,600 & & 0,733 & 0,533 & 0,600 \\
0 & 0,400 & 0,467 & 0,467 & 0,267 & & 0,400 & 0,267 \\
0,267 & 0,467 & 0,267 & 0,267 & 0,467 & 0,600 & & 0,600 \\
0,200 & 0,400 & 0,667 & 0,400 & 0,400 & 0,733 & 0,400 &
\end{array}\right]
$$

Figura 8: Matriz de Discordância

$$
\mathrm{D}=\left[\begin{array}{cccccccc} 
& 0,022 & 0,198 & 0,348 & 0,167 & 0 & 0,040 & 0,704 \\
0,360 & & 0,470 & 0,627 & 0,430 & 0,188 & 0,068 & 0,975 \\
0,247 & 0,070 & & 0,263 & 0,414 & 0,085 & 0,088 & 0,505 \\
0,120 & 0,033 & 0 & & 0,151 & 0,068 & 0,051 & 0,355 \\
0,191 & 0 & 0,327 & 0,477 & & 0,137 & 0,017 & 0,832 \\
0,621 & 0,358 & 0,398 & 0,637 & 0,788 & & 0,286 & 0,904 \\
0,365 & 0,072 & 0,495 & 0,645 & 0,502 & 0,189 & & 1 \\
0,500 & 0,237 & 0,254 & 0,516 & 0,668 & 0,024 & 0,165 &
\end{array}\right]
$$




\begin{tabular}{ccccccccc}
\hline & $A 1$ & $A 2$ & $A 3$ & $A 4$ & $A 5$ & $A 6$ & $A 7$ & $A 8$ \\
$A 1$ & - & 1 & 1 & 0 & 0 & 1 & 1 & 0 \\
$A 2$ & 0 & - & 0 & 0 & 0 & 0 & 0 & 0 \\
$A 3$ & 0 & 1 & - & 0 & 0 & 0 & 1 & 0 \\
$A 4$ & 0 & 0 & 0 & - & 0 & 0 & 0 & 0 \\
$A 5$ & 0 & 1 & 0 & 0 & - & 0 & 1 & 0 \\
$A 6$ & 0 & 0 & 0 & 0 & 0 & - & 0 & 0 \\
$A 7$ & 0 & 0 & 0 & 0 & 0 & 0 & - & 0 \\
$A$ & 0 & 0 & 0 & 0 & 0 & 1 & 0 & - \\
\hline
\end{tabular}

A partir da análise do grafo da Figura 10, que apresenta o kernel das relações de superação apresentados na Figura 9, há 04 (quatro) municípios que se encontram no subconjunto não-dominado: Italva, Porciúncula, Varre-Sai e Itaocara para escolher 01 (um) município na mesorregião Noroeste Fluminense. Neste caso, em que 04 (quatro) municípios ficaram nas mesmas posições de melhores alternativas e o problema recai sobre a definição de apenas um, fica demonstrado que o AMD, em qualquer situação, não prescinde da manifestação e posicionamento do decisor. Neste caso, também se apresenta como possibilidade, a aplicação de método multicritério, especificamente, para escolha do município dentre as 04 (quatro) alternativas. Os métodos Electre III ou o método AHP, úteis para a seleção de uma única alternativa de ação, poderiam ser aplicados para auxiliar o gestor na tomada de decisão do problema II.

Figura 10: Relação de sobreclassificação das alternativas

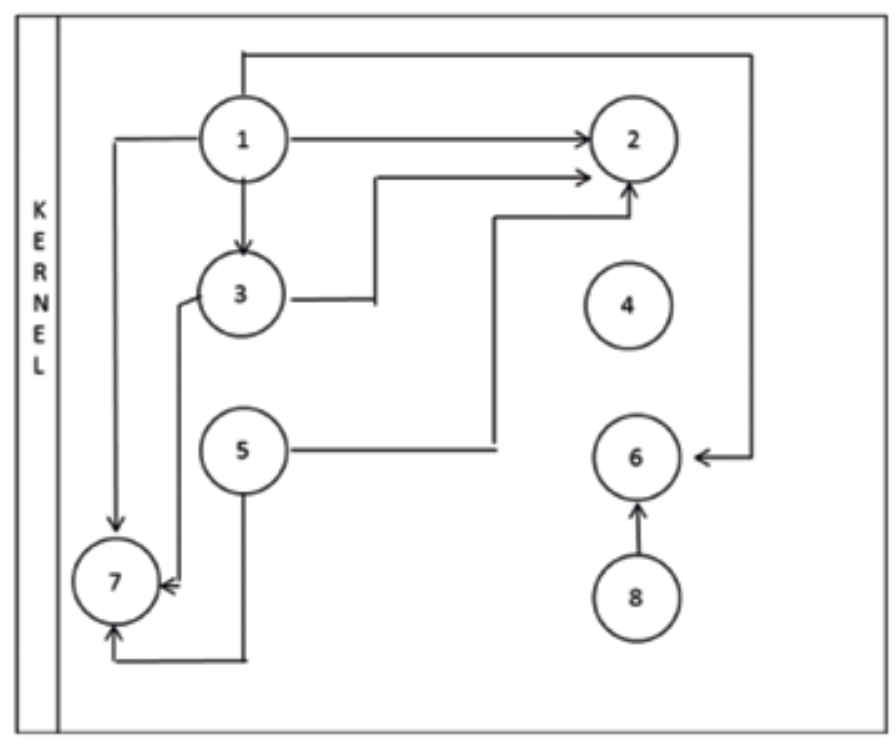

\section{iii) Problema III}

O terceiro problema abordado neste trabalho propõe-se a selecionar 03 municípios na mesorregião Baixadas Litorâneas expandidas. A Tabela 4 apresenta o desempenho dos municípios candidatos a receberem polo EaD do IFFluminense. Pode-se observar 
na Tabela 4 que os municípios de Rio das Ostras (A1) e Araruama (A3) se destacam nos critérios 'Habitantes' e 'Matrículas EM'. Os municípios de Silva Jardim (A2) se destaca no critério 'Distância rodoviária'. Pelo critério 'IDHM', o município de Silva Jardim (A2) é o que menos se potencializa, enquanto que Iguaba Grande (A5) se destaca no critério IDEB.

Tabela 4: Desempenho das alternativas (An) a luz dos critérios. Entre parênteses os valores normalizados

\begin{tabular}{|c|c|c|c|c|c|}
\hline \multirow[b]{2}{*}{ ALTERNATIVAS } & \multicolumn{5}{|c|}{ CRITÉRIOS } \\
\hline & $\begin{array}{l}\text { Habitantes }{ }^{4} \\
\text { (número total) }\end{array}$ & IDHM & $\begin{array}{l}\text { Matrículas EM } \\
\text { (número total) }\end{array}$ & IDEB & $\begin{array}{c}\text { Distância } \\
\text { rodoviária } \\
\text { (em Km) }\end{array}$ \\
\hline \multirow{2}{*}{ Rio das Ostras (A1) } & 46.043 & 0,773 & 4.454 & 4,7 & $27,1^{1}$ \\
\hline & $(0,252)$ & $(0,153)$ & $(0,259)$ & $(0,169)$ & $(0,114)$ \\
\hline \multirow{2}{*}{ Silva Jardim (A2) } & 8.594 & 0,654 & 735 & 3,8 & $62,2^{2}$ \\
\hline & $(0,047)$ & $(0,129)$ & $(0,043)$ & $(0,137)$ & $(0,262)$ \\
\hline \multirow{2}{*}{ Araruama (A3) } & 43.363 & 0,718 & 4.052 & 3,7 & $40,5^{2}$ \\
\hline & $(0,237)$ & $(0,142)$ & $(0,235)$ & $(0,133)$ & $(0,170)$ \\
\hline \multirow{2}{*}{ Armação dos Búzios (A4) } & 11.795 & 0,728 & 1.616 & 4,4 & $24,6^{2}$ \\
\hline & $(0,064)$ & $(0,144)$ & $(0,094)$ & $(0,158)$ & $(0,103)$ \\
\hline \multirow{2}{*}{ Iguaba Grande (A5) } & 8.355 & 0,761 & 1.206 & 3,4 & $25,9^{2}$ \\
\hline & $(0,046)$ & $(0,151)$ & $(0,070)$ & $(0,122)$ & $(0,109)$ \\
\hline \multirow{2}{*}{ São Pedro da Aldeia (A6) } & 35.647 & 0,712 & 2.616 & 3,7 & $14,4^{2}$ \\
\hline & $(0,195)$ & $(0,141)$ & $(0,152)$ & $(0,133)$ & $(0,061)$ \\
\hline \multirow{2}{*}{ Saquarema (A7) } & 29.233 & 0,709 & 2.527 & 4,1 & $43,0^{3}$ \\
\hline & $(0,160)$ & $(0,140)$ & $(0,147)$ & $(0,147)$ & $(0,181)$ \\
\hline
\end{tabular}

Legenda:

1 = Distância entre o município e aquele com campus presencial mais próximo, neste caso, o município de Macaé;

2 = Distância entre o município e aquele com campus presencial mais próximo, neste caso, o município de Cabo Frio;

3 = Distância entre o município e aquele com campus presencial mais próximo, neste caso, o município de Maricá; IDHM = Índice de Desenvolvimento Humano Municipal; IDEB = Índice de Desenvolvimento da Educação Básica, Matrículas EM = matrículas no Ensino Médio.

$4=$ Entre 15 e 39 anos.

Fonte: Os autores com base nos dados do IBGE, INEP, PNUD e Google Earth.

As Figuras 11 e 12 apresentam as matrizes de concordância e discordância, respectivamente, do problema III, que pretende apontar alternativas potenciais de escolha na mesorregião Baixadas Litorâneas. A elaboração destas matrizes considerara os mesmos limiares de 'p' e ' $q$ ' assumidos nas modelagens anteriores.

Figura 11: Matriz de Concordância

$$
\mathrm{C}=\left[\begin{array}{ccccccc} 
& 0,400 & 0,400 & 0,733 & 0,733 & 0,733 & 0,400 \\
0,600 & & 0,800 & 0,600 & 0,867 & 0,800 & 0,600 \\
0,600 & 0,200 & & 0,800 & 1 & 0,533 & 0,200 \\
0,267 & 0,400 & 0,200 & & 0,667 & 0,533 & 0,200 \\
0,267 & 0,133 & 0 & 0,333 & & 0,333 & 0 \\
0,267 & 0,200 & 0,267 & 0,467 & 0,667 & & 0,200 \\
0,600 & 0,400 & 0,800 & 0,800 & 1 & 0,800 &
\end{array}\right]
$$


Figura 12: Matriz de Discordância

$$
\mathrm{D}=\left[\begin{array}{ccccccc}
1 & 0,683 & 0,261 & 0,041 & 0,011 & 0,056 & 0,309 \\
0,166 & 0,422 & & 0,116 & 0 & 0,005 & 0,067 \\
0,866 & 0,732 & 0,798 & & 0,025 & 0,603 & 0,441 \\
0,953 & 0,707 & 0,885 & 0,166 & & 0,690 & 0,528 \\
0,494 & 0,930 & 0,508 & 0,199 & 0,224 & & 0,557 \\
0,518 & 0,374 & 0,410 & 0,050 & 0 & 0,162 &
\end{array}\right]
$$

Fonte: Autoria própria.

A Figura 13 é a matriz de superação, que indica a relação final de superação entre as alternativas do Problema III.

Figura 13: Matriz de Superação

\begin{tabular}{|c|c|c|c|c|c|c|c|}
\hline & $A 1$ & $A 2$ & $A 3$ & $A 4$ & $A 5$ & $A 6$ & $A 7$ \\
\hline$A 1$ & - & 0 & 0 & 1 & 1 & 1 & 0 \\
\hline$A 2$ & 0 & - & 0 & 0 & 1 & 0 & 0 \\
\hline$A 3$ & 0 & 0 & - & 1 & 1 & 0 & 0 \\
\hline$A 4$ & 0 & 0 & 0 & - & 0 & 0 & 0 \\
\hline$A 5$ & 0 & 0 & 0 & 0 & - & 0 & 0 \\
\hline A6 & 0 & 0 & 0 & 0 & 0 & - & 0 \\
\hline A7 & 0 & 0 & 0 & 1 & 1 & 1 & - \\
\hline
\end{tabular}

A Figura 14 apresenta o kernel das relações de superação apresentados Figura 13, que seleciona como melhores alternativas os municípios de Rio das Ostras (A1), Silva Jardim (A2), Araruama (A3) e Saquarema (A7), que exigirá também do julgamento do decisor, uma vez que o foco do problema está na escolha de 03 municípios das Baixadas Litorâneas ou a aplicação de método multicritério para auxílio à decisão como foi o caso do problema II.

Figura 14: Relação de sobreclassificação das alternativas

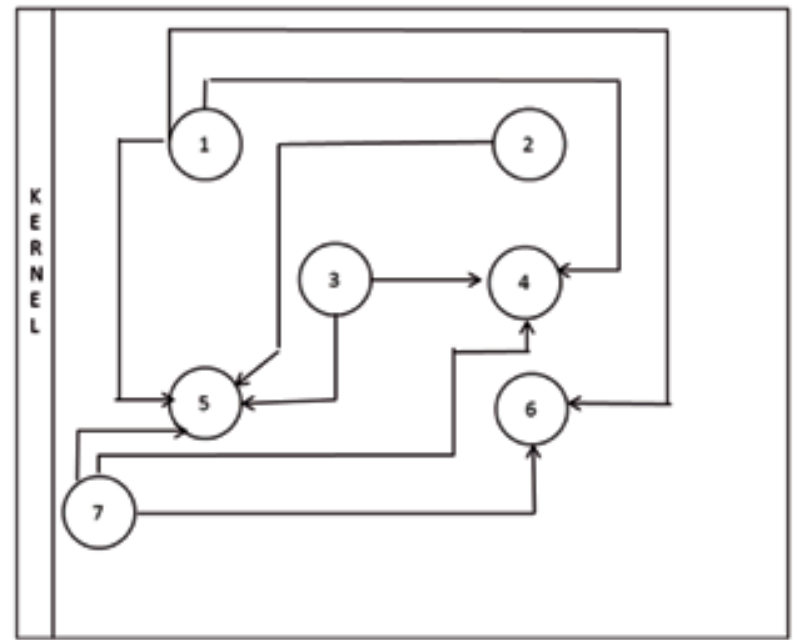




\section{Considerações finais}

O presente Artigo aborda a problemática de localização de seis polos EaD em municípios integrantes de três mesorregiões do Estado do Rio de Janeiro para uma instituição de educação profissional e tecnológica. Os resultados alcançados com a aplicação da metodologia Electre I demonstram a utilidade dos métodos multicritérios de apoio à decisão. No entanto, o método apresenta um grau de subjetividade na definição dos limiares de concordância e discordância, e que pode influenciar no resultado final. A Tabela 5 apresenta um sumário dos resultados apresentados nos problemas I, II e III deste estudo. Pode-se observar que o método multicritério ELECTRE I de apoio à decisão indica, em todos os casos, um número de alternativas de ação maior do que o número possível de polos a serem implantados.

Tabela 5: Municípios mais promissores a receberem um polo de Educação a Distância nas regiões estudadas

\begin{tabular}{|c|c|c|c|}
\hline PROBLEMA & REGIÃO & $\begin{array}{l}\text { NÚMERO DE POLOS A SEREM } \\
\text { IMPLANTADOS }\end{array}$ & $\begin{array}{l}\text { MUNICÍPIOS MAIS PROMISSORAS } \\
\text { INDICADOS NESTE TRABALHO }\end{array}$ \\
\hline \multirow{2}{*}{1} & \multirow{2}{*}{ Norte Fluminense } & \multirow{2}{*}{02} & São Fidélis \\
\hline & & & São Francisco do Itabapoana \\
\hline \multirow{4}{*}{ II } & \multirow{4}{*}{ Noroeste Fluminense } & \multirow{4}{*}{01} & Italva \\
\hline & & & Porciúncula \\
\hline & & & Varre-Sai \\
\hline & & & Itaocara \\
\hline \multirow{4}{*}{ III } & \multirow{4}{*}{ Baixadas Litorâneas } & \multirow{4}{*}{03} & Rio das Ostras \\
\hline & & & Silva Jardim \\
\hline & & & Araruama \\
\hline & & & Saquarema \\
\hline
\end{tabular}

Fonte: Elaboração própria.

O método Electre I, sem prescindir de aspectos ligados ao decisor, favorece a transparência nos processos decisórios dos gestores. Porém, vale renovar a afirmação de que nenhum tipo de instrumento ou ferramenta pode ser considerado pela sua qualidade que supera a condição de deliberador finalístico do decisor. No caso do resultado para escolha dos dois municípios do Norte Fluminense, que definiu São Fidelis e São Francisco de Itabapoana, mesmo que este resultado tenha coincidido com o número proposto para esta mesorregião, não significa que o gestor acatará de forma plena esta sugestão como sua decisão final, uma vez que há outros fatores que podem contribuir ou não para a validação dos resultados. Ainda sobre o aspecto locacional, sugere-se a aplicação de métodos AMD para definição da microlocalização, ou seja, em que local do município deve ser implantado o polo EaD.

Em termos de AMD, a escola americana e a francesa têm se destacado. A francesa, com mais evidência nos métodos Electre e Promethee, e no caso americano, o método AHP. A literatura não deixa muito claro qual método multicritério é mais indicado para as diversas problemáticas. No entanto, é inegável que há uma diferença que reside na concepção do método, uma vez que, a escola americana atua mais na questão do ordenamento, de forma mais classificatória e hierarquizada, enquanto o princípio da escola francesa, ainda que não impeça estabelecer a relação hierárquica, ressalta mais o aspecto coletivo, ou seja, evidencia menos a hierarquia, na medida em que o Electre I se define como um método que escolhe o conjunto das melhores alternativas dentro das alternativas apresentadas. De forma preliminar, consegue-se intuir esta diferença como reflexo do modus vivendi das sociedades americana e europeia, em que aspectos de competitividade e de hierarquização estão matizados na cultura americana. 


\section{Referências bibliográficas}

ALMEIDA, Adiel Teixeira de. Processo de decisão nas organizações: construindo modelos de decisão multicritério. São Paulo: Editora Atlas, 2013.

ALMEIDA, Adiel Teixeira et al. A new method for elicitation of criteria weights in additive models: Flexible and interactive tradeoff. European Journal of Operational Research, $v$. 250, n. 1, p. 179-191, 2016.

AQUINO, C. N. P.; PEREIRA, L. A. C.; ERTHAL JUNIOR, M. Modelagem multicritério para estabelecimento de polos de Educação a Distância nas mesorregiões do Instituto Federal Fluminense. R. Tecnol. Soc., Curitiba, v. 13, n. 28, p. 90-110, mai./ago. 2017. Disponível em: 〈https://periodicos.utfpr.edu.br/rts/article/view/5296/pdf〉. Acesso em: 20 de mai. 2017.

ARAÚjO, Jéfferson Jesus de; AMARAL, Thiago Magalhães. Aplicação do método ELECTRE I para problemas de seleção envolvendo projetos de desenvolvimento de software livre. GEPROS. Gestão da Produção, Operações e Sistemas, Bauru, ano 11, n. 2, abr-jun/2016, p. 121-137.

COSTA, Helder Gomes. Graphical interpretation of outranking principles: Avoiding misinterpretation results from ELECTRE I". Journal of Modelling in Management, v. 11, n. 1, pp.26-42, 2016.

ELGÜN, Mahmut Nevfel. The Foundation Basis And Selection of Set Up Locations of Freight Villages in The National And International Transportation \& Trade. Journal of Economics \& Administrative Science, v. 13(2), pp. 203-226, 2011.

FIGUEIRA, José; MOUSSEAU, Vincent, ROY, Bernard. ELECTRE Methods. In: FIGUEIRA, José; GRECO, Salvatore; EHRGOTT, Matthias (Ed.). Multiple criteria decision analysis: state of the art surveys. International Series in Operations Research \& Management Science. Boston: Springer Science+Bussines Media; pp. 133-162, 2005.

GOMES, Luiz Flavio Autran Monteiro; ARAYA, Marcela Cecilia González; CARIGNANO, Claudia. Tomada de decisões em cenários complexos. São Paulo: Thomson, 2004.

HELMANN, Kurtt Schamme; MARÇAL, Rui Francisco Martins. Método multicritério de apoio à decisão na gestão da manutenção: aplicação do método ELECTRE na seleção de equipamentos críticos para processo. Revista Gestão Industrial, v. 03, n. 01, p. 123-133, 2007.

LEITE, Igor Michel Santos; FREITAS, Felipe Fonseca Tavares de. Análise comparativa dos métodos de apoio multicritério a decisão: AHP, ELECTRE e PROMETHEE. In.: XXXII Encontro Nacional de Engenharia de Produção, 2012, Bento Gonçalves. Anais ... Bento Gonçalves: ABEPRO, 2012, $11 \mathrm{p}$.

MELLO, J.C.C.B.S. et al. Use of ordinal multi-criteria methods in the analysis of the Formula 1 World Championship. In: Cadernos EBAPE.BR., v. 3, n. 2, p. 1-8, 2005.

MENDONÇA, Fabricio Molica de; INFANTE, Carlos Eduardo Durange de C.; VALLE, Rogerio Aragão B. do. Aplicação do método ELECTRE III na avaliação de desempenho de redes de empresas produtoras de artesanato: o caso da região de Minas Gerais. Revista Symposium, ed. 16, v. 8, n. 2, p 65-81, Jul/Dez 2010.

ROY, Bernard. Paradigms and Challenges. In: FIGUEIRA, José; GRECO, Salvatore; EHRGOTT, Matthias (Ed.). Multiple criteria decision analysis: state of the art surveys. International Series in Operations Research \& Management Science. Boston: Springer Science+Bussines Media; 2005.

ROY, B. e BOUYSSOU, D. Aide multicritère à la décision: méthodes et cas. Paris: Econômica, 1993. 
SIQUEIRA, G. B. A., FILHO A. T. D. A. Aplicação do método ELECTRE I para seleção de ideias de inovação. In: SIMPÓSIO BRASILEIRO DE PESQUISA OPERACIONAL, 43, 2011, 15-18 ago, Ubatuba-SP. Anais... Ubatuba-SP: SBPO, 2012. p.3322-3332. Disponível em: 〈http://www.din.uem.br/sbpo/sbpo2011/pdf/88080.pdf 〉.

SILVA, E.L. e MENEZES, E.M. Metodologia da pesquisa e elaboração de dissertação. Florianópolis: UFSC, 138p, 2005.

www.ibge.gov.br

www.br.undp.org

www.inep.gov.br 